\title{
Active Surveillance of Renal Masses: An Analysis of Growth Kinetics and Clinical Outcomes Stratified by Radiological Characteristics at Diagnosis
}

Ryan Dorin, Max Jackson, Antonio Cusano, Peter Haddock, Halil Kiziloz, Anoop Meraney, Steven Shichman

Hartford Hospital healthcare Group - Urology, USA

\section{ABSTRACT}

AIMS: To determine the growth rate of renal masses (RMs) under active surveillance (AS), and to describe the clinical outcome of AS patients.

Materials and Methods: We conducted a retrospective review of an AS database to obtain demographics, radiological and pathologic characteristics and RM size of patients. RMs were followed at 6-12 month intervals for $\geq 1$ year with computed tomography (CT), magnetic resonance imaging (MRI), or renal ultrasound. Kaplan-Meier analysis determined the annual likelihood of intervention. RMs were divided into 3 radiographic subcategories (solid, cystic, and angiomyolipoma). A linear regression model determined RM growth rates.

Results: 131 RMs in 114 patients were included. Median age, Charlson Comorbidity Index score and mean follow-up were 69.1 years, 4.0 and $4.2 \pm 2.6$ years, respectively. Maximal tumor diameter (MTD) at diagnosis was $2.1 \pm 1.3 \mathrm{~cm}$. 49 RMs exhibited negative or zero net growth. Mean MTD growth rate for all RMs was 0.72 \pm 3.2 (95\% CI: 0.16-1.28) mm/ year. When stratified by MTD at diagnosis, mean RM growth rates were $0.84,0.84,0.44$, 0.74 and $0.71 \mathrm{~mm} /$ year for RMs $<1 \mathrm{~cm}, 1-<2 \mathrm{~cm}, 2-<3 \mathrm{~cm}, 3-<4 \mathrm{~cm}$ and $\geq 4 \mathrm{~cm}$, respectively $(\mathrm{p}<0.01)$. The 5 and 10-year freedom from intervention rates were 93.1\% and 88.5\%, respectively. There was a single case of suspected metastases, but no deaths related to kidney cancer.

Conclusions: RMs under AS grew slowly, and had a low incidence of requiring surgical intervention and progression. Solid enhancing masses grew slowly, and were more likely to trigger intervention. AS should be considered for selected patients with small RMs.

\section{ARTICLE INFO}

\section{Key words:}

Watchful Waiting;

Chronotherapy;

Angiomyolipoma; Kinetics

Int Braz J Urol. 2014; 40: 627-36

Submitted for publication:

September 23, 2013

\section{Accepted after revision:}

March 13, 2014

\section{INTRODUCTION}

The use of high resolution cross-sectional imaging has resulted in the detection of an increasing number of small, incidental renal masses (RMs), a significant proportion of which are subsequently found to be benign on pathologic examination (1).

Recent studies have highlighted the benefit of renal preservation in patients undergoing treatment for renal cell carcinoma (RCC) and have demonstrated that RMs typically exhibit slow growth rates and a low incidence of metastatic spread $(2,3)$. These findings suggest that active surveillance (AS) of RM patients may be a viable management strategy, particularly for those patients at greater risk for perioperative complications or chronic kidney disease (4).

Although AS is gaining acceptance as a RM management strategy, standardized protocols 
are lacking, and clinicians may feel compelled towards surgical intervention owing to uncertainty over growth potential and the risk of disease progression. We examined our institutional experience with AS of RMs to characterize their growth and risk of progression, and attempted to risk stratify RMs based on radiologic characteristics at time of diagnosis. It was our objective to utilize these data to optimize active surveillance protocols, with the aim of minimizing the morbidity experienced by patients incidentally diagnosed with RMs.

\section{MATERIALS AND METHODS}

The study was approved by the Hartford Hospital Institutional Review Board. Data from 114 patients, with a total of 131 RMs, who underwent active surveillance (AS) of a RM between January 2002 and June 2011, were retrieved from our IRB-approved renal mass active surveillance database. Patient demographics and clinical, radiologic, and pathologic RM characteristics were tabulated. Patients were diagnosed either incidentally or upon clinical presentation using ultrasonography (US), computerized tomography (CT) or magnetic resonance imaging (MRI). Patient follow-up occurred at 6-12 month intervals using CT, MRI or US. Key factors that influenced undertaking a RM biopsy included (i) growth rate, (ii) the worsening of a suspicious feature on imaging while on AS (i.e. more enhancement or more definitive solid component), (iii) patient preference due to emotional distress/concern and (iv) significant patient comorbidities which would favor AS in the presence of low grade renal cell carcinoma (RCC). However, the decision to biopsy was made at the discretion of the treating physician following patient consultation.

An attending radiologist and urologist reviewed all images to determine RM size, appearance, contrast accumulation and fat content. Simple cystic lesions and cystic lesions with thin septations or walls without contrast enhancement (Bosniak Type I and II) were excluded. There were no prospectively established selection criteria for the patients undergoing AS.

In our institution, RMs are selected for AS based on tumor and patient characteristics, inclu- ding each patient's desire to undergo intervention. In general, solid RMs $<3 \mathrm{~cm}$ in diameter are considered appropriate for AS, as well as angiomyolipomas (AML) $<4 \mathrm{~cm}$ in diameter. Larger tumors are also considered for AS in cases of severe patient comorbidity, solitary kidney, or the presence of Bosniak IIF cysts. Prior to entering the AS program, patients are counseled regarding the impact of comorbidities, age, the risk of surgery, a desire to undergo surgery, and RM size and appearance. All patients are counseled that in the event that their RM showed significant growth on follow-up, surgical intervention might be considered. Only patients who were followed for $>12$ months and had $\geq 2$ imaging procedures on follow-up were included in the analysis.

The maximal tumor diameter (MTD) of RMs on imaging was determined, and recorded at time of diagnosis and on each follow-up visit. Specifically, a linear regression model was utilized to construct a "line of best fit" for the growth of each individual mass, and the growth rate was calculated from its slope. The average growth rate of each radiographic RM subgroup was calculated as the mean value of their growth rate slopes. Kaplan-Meier analysis was used to estimate the annual likelihood of requiring intervention. Statistical tests including (i) t-test, (ii) Mann-Whitney U test, (iii) ANOVA, and (iv) Kruskal-Wallis test were used depending on the assumption of homogeneity of the variances. Comparison between the mean RM growth rates of the solid, cystic and AML groups (tests i and ii) and between RMs stratified according to their initial size (tests iii and iv) were performed. The growth rate of RMs with a positive net growth on follow-up, and histopathologically proven to be RCC, was also calculated. All statistical analyses were performed using SPSS v17.0 (Chicago, IL).

\section{RESULTS}

Data from 114 patients under AS (60 female; $52.6 \%$ ) for 131 RMs were available and met the study inclusion criteria. In this group, median patient age at diagnosis was 69.1 years (range: 20.7-89.7), median Charlson Comorbidity Index (CCI) score was 4 (range: 0-8), and mean follow-up time was $4.2 \pm 2.6$ years (range: $0.9-15.3$ ). The 
mean and median number of follow-up studies was $5.9 \pm 2.6$ and 6.0, respectively (range 2-17). Patient demographics and RM characteristics are summarized in Table-1. At diagnosis, the mean maximal tumor diameter (MTD) was $2.1 \pm 1.3 \mathrm{~cm}$ (solid: $1.9,0.7-4$; cystic: $2.84 \pm 2.1,0.9-9.2$; AML: $1.63 \pm 1.16,0.4-4.6 \mathrm{~cm})$. At the most recent patient follow-up visit, the mean MTD was $2.36 \pm 1.63 \mathrm{~cm}$ (solid: $2.18 \pm 1.0,0.3-5.3$; cystic $3.13 \pm 2.8 \mathrm{~cm}, 0.6-$ 11 ; AML 2.04 $\pm 1.08,0.4-3.9 \mathrm{~cm})$.

Table 1 - Demographics and clinical data of patients and RMs (data shown as mean \pm SD where appropriate).

\begin{tabular}{|c|c|c|c|}
\hline & & & Number of masses (\%) \\
\hline Number of patients/Gender (M/F) & & $114 / 54 / 60$ & \\
\hline Number of renal masses & & 131 & \\
\hline Patient age (years) (mean $\pm S D$; median; range) & & $65.4 \pm 14.2 ; 69.1 ; 20.7-89.7$ & \\
\hline Total follow-up time (years) $($ mean $\pm S D$; range) & & $4.2 \pm 2.6(0.9-15.3)$ & \\
\hline $\begin{array}{l}\text { Number of follow-up studies (mean; median; } \\
\text { range) }\end{array}$ & & $5.9 \pm 2.6 ; 6 ; 2-17$ & \\
\hline BMI $\left(\mathrm{kg} / \mathrm{m}^{2}\right)($ mean $\pm \mathrm{SD}$; median; range) & & $27.4 \pm 4.8 ; 26.4 ; 18.6-39.5$ & \\
\hline $\mathrm{CCl}$ score (mean $\pm \mathrm{SD}$; median; range) & & $3.4 \pm 1.5 ; 4 ; 0-8$ & \\
\hline Initial serum creatinine $(\mathrm{mg} / \mathrm{mL})$ (median) & & 1.0 & \\
\hline Final serum creatinine $(\mathrm{mg} / \mathrm{mL})$ (median) & & 1.1 & \\
\hline \multirow[t]{3}{*}{$\begin{array}{l}\text { Radiological appearance at diagnosis (number of } \\
\text { tumors; \%) }\end{array}$} & Solid enhancing & & $77(58.7)$ \\
\hline & AML & & $25(19.1)$ \\
\hline & Cystic & & $29(22.1)$ \\
\hline \multirow[t]{6}{*}{$\begin{array}{l}\text { Maximal tumor diameter growth rate (mm/year) } \\
(\text { mean } \pm \mathrm{SD} ; 95 \% \mathrm{Cl})\end{array}$} & All masses & $0.72 \pm 3.2(0.16-1.28)$ & $131(100)$ \\
\hline & Solid & $0.94 \pm 1.9(0.5-1.4)$ & $77(58.7)$ \\
\hline & AML & $0.75 \pm 4.4(-1.1-2.6)$ & $25(19.1)$ \\
\hline & Cystic & $0.1 \pm 4.4(-1.63-1.81)$ & $29(22.1)$ \\
\hline & $\begin{array}{l}\text { RMs requiring } \\
\text { intervention }\end{array}$ & $2.56 \pm 1.2(3.2-1.9)$ & $15(11.5)$ \\
\hline & $\begin{array}{l}\text { RMs with positive } \\
\text { growth }\end{array}$ & $0.21 \pm 0.2(0.26-1.7)$ & $82(62.6)$ \\
\hline \multirow[t]{5}{*}{$\begin{array}{l}\text { RM growth rate based on size at diagnosis }(\mathrm{mm} / \\
\text { year) (mean } \pm S D ; 95 \% \mathrm{Cl})\end{array}$} & $<1.0 \mathrm{~cm}$ & $0.84 \pm 4.9(-1.5-3.17)$ & $20(15.2)$ \\
\hline & $1.0-<2.0 \mathrm{~cm}$ & $0.84 \pm 1.6(0.4-1.28)$ & $54(41.2)$ \\
\hline & $2.0-<3.0 \mathrm{~cm}$ & $0.44 \pm 2.9(-0.61-1.50)$ & $33(25.2)$ \\
\hline & $3.0-<4.0 \mathrm{~cm}$ & $0.74 \pm 1.5(-0.32-1.79)$ & $11(8.4)$ \\
\hline & $\geq 4.0 \mathrm{~cm}$ & $0.71 \pm 5.7(-2.88-4.30)$ & $13(9.9)$ \\
\hline
\end{tabular}


Figure 1 - Exemplary CT scans of renal masses under active surveillance. a \& b: solid enhancing renal mass (indicated by arrows), c: complex cystic mass, d: angiomyolipoma.
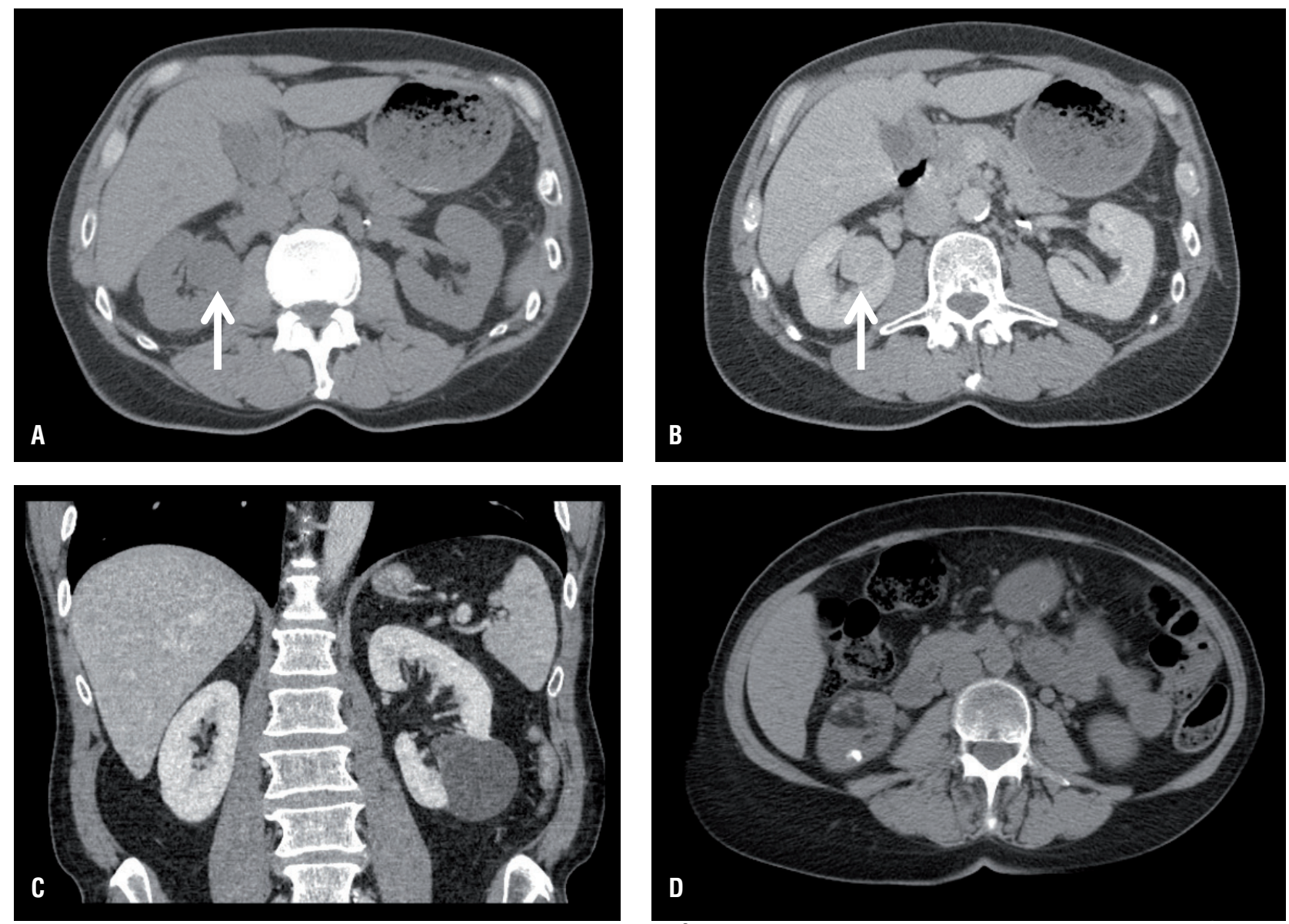

Mean MTD growth rate for all RMs was $0.72 \pm 3.2 \quad$ (95\% $\quad$ CI: $0.16-1.28) \quad \mathrm{mm} /$ year (solid: $0.94 \pm 1.9$ (95\% CI: 0.5-1.4) mm/year; cystic: $0.1 \pm 4.4$ (95\% CI: -1.63-1.81) mm/year; AML: $0.75 \pm 4.4$ (95\% CI: -1.1-2.6) mm/year; $\mathrm{p}<0.01$ for all pairwise comparisons). The growth curves of RMs under surveillance are plotted in Figure-2. When stratified by MTD at diagnosis, mean RM growth rates were $0.84 \pm 4.9$ (95\% CI: -1.5-3.17), 0.84 \pm 1.6 (95\% CI: 0.41.28), $0.44 \pm 2.9$ (95\% CI: $-0.61-1.5), 0.74 \pm 1.5$ (95\% CI: $-0.32-1.79)$ and $0.71 \pm 5.7$ (95\% CI: $-2.88-4.3) \mathrm{mm} /$ year for RMs $<1 \mathrm{~cm}, 1-<2 \mathrm{~cm}, 2-<3 \mathrm{~cm}, 3-<4 \mathrm{~cm}$ and $\geq 4 \mathrm{~cm}$ at diagnosis, respectively ( $<<0.01$; Figure- 3 ). 82 RMs (62.6 \%) exhibited positive net growth, while 49 (37.4\%) exhibited negative or zero net growth during AS (solid masses: 25/77, 32.5 \%; AMLs: 7/25, $28 \%$ and cystic masses: 17/29, $58.6 \%$ ).

Therapeutic intervention was performed on 15 RMs initially under AS. Of these, 13 of the masses were solid enhancing masses and two were angiomyolipomas. (Table-2). Interventions performed on these masses included 7 partial nephrectomies, 6 cryoablations, and one selective embolization for AML, at a mean time from diagnosis of $4.77 \pm 2.48$ years (median: 4.2 years; $1.1-10.48$ ) and at a mean tumor size of $2.83 \pm 0.63 \mathrm{~cm}(2-3.8 \mathrm{~cm})$ (Table-2). The mean MTD growth rate of RMs eventually undergoing surgical intervention was $2.57 \pm 1.2 \mathrm{~mm} /$ year. Indications for interventions were mass growth to a MTD $>3 \mathrm{~cm}$ in 5 RMs. The remaining RM underwent cryoablation due to patient anxiety in a mass measuring $<2 \mathrm{~cm}$ with minimal growth. The overall 5 and 10-year freedom from intervention rates were 93.1\% and $88.5 \%$, respectively (Figure-4). 
Figure 2 - A: Time dependent changes in maximal renal mass diameter for all renal masses. B: Time dependent changes in maximal renal mass diameter stratified by tumor type.
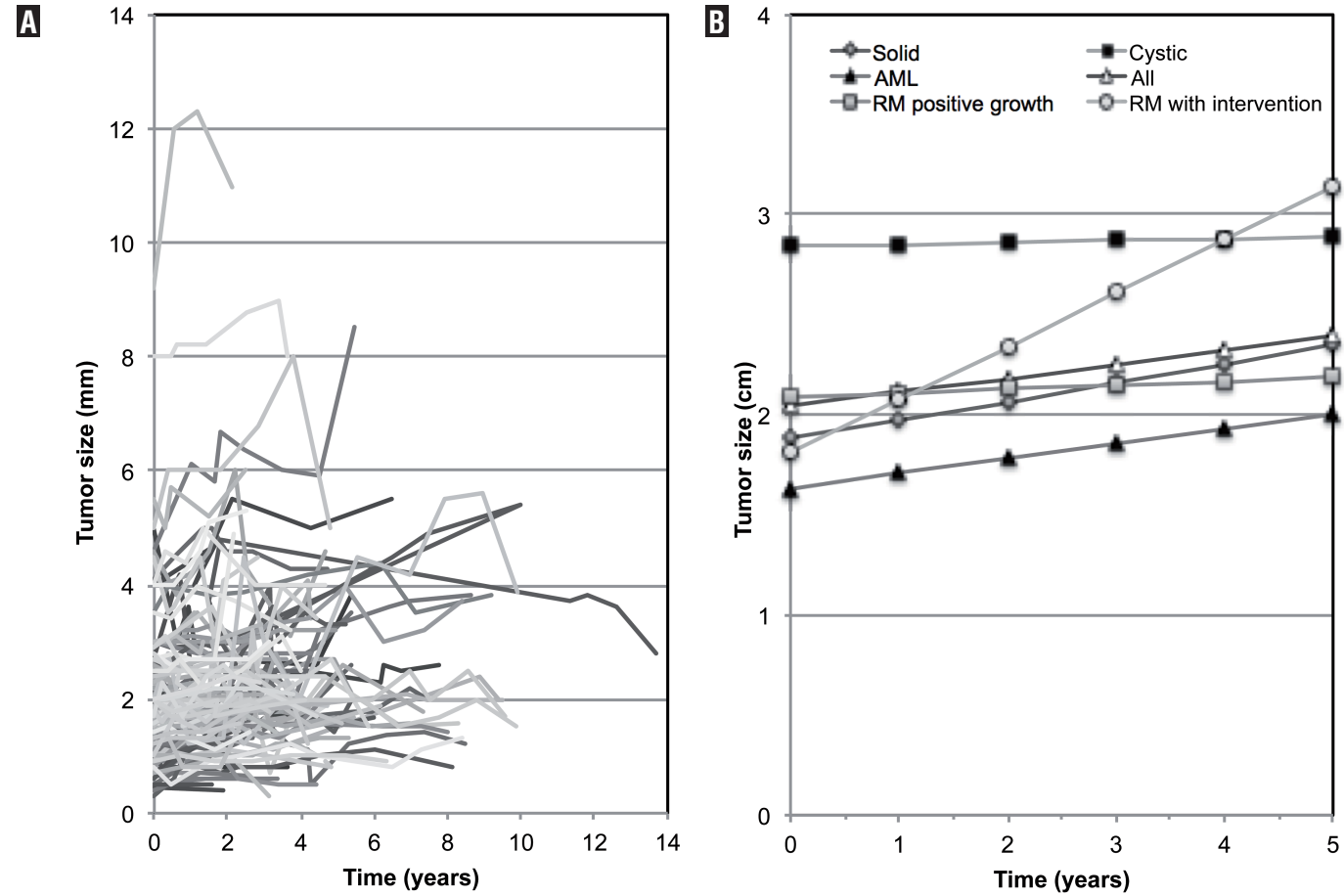

Figure 3 - Renal mass growth rates ( $\mathrm{mm} / \mathrm{year})$ stratified according to A: maximal tumor diameter at diagnosis and B: tumor type (data shown as mean $\pm 95 \% \mathrm{Cl}$, median, $1^{\text {st }}$ and $3^{\text {rd }}$ quartiles).

A

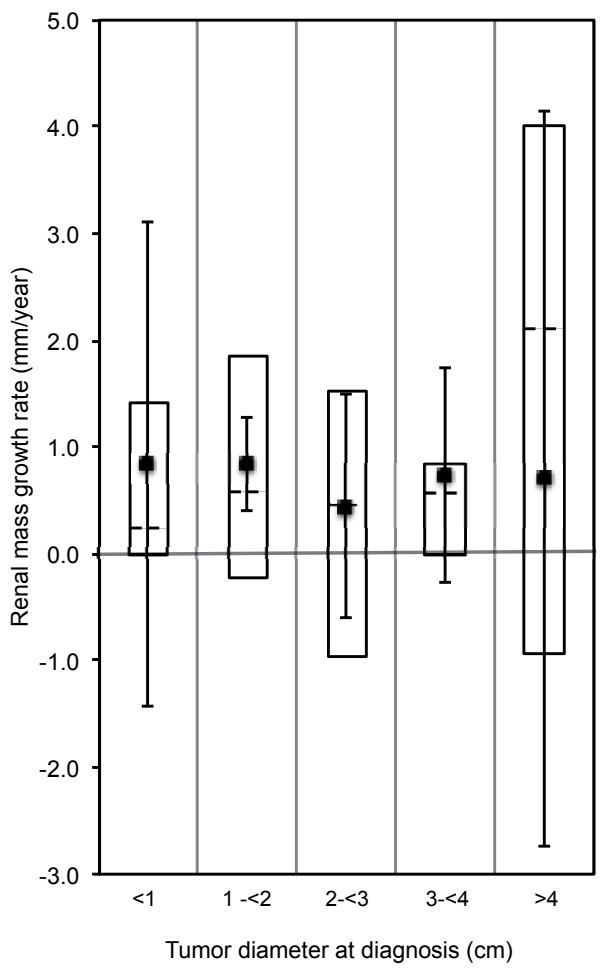

B

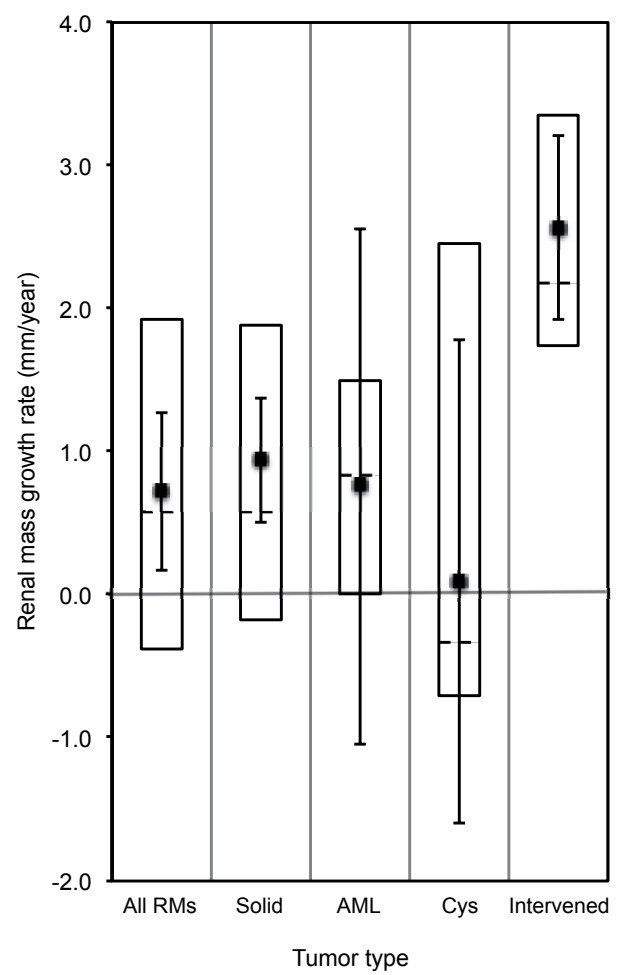


Table 2 - Renal masses under AS which progressed to surgical intervention.

\begin{tabular}{|c|c|c|c|c|c|c|c|c|}
\hline Gender & $\begin{array}{c}\text { Age at } \\
\text { Diagnosis } \\
\text { (years) }\end{array}$ & $\begin{array}{l}\text { Type of } \\
\text { Mass }\end{array}$ & $\begin{array}{c}\text { Initial Mass } \\
\text { Size }(\mathrm{cm})\end{array}$ & $\begin{array}{c}\text { Final Mass } \\
\text { Size }(\mathrm{cm})\end{array}$ & $\begin{array}{c}\text { Growth rate } \\
(\mathrm{mm} / \mathrm{yr})\end{array}$ & $\begin{array}{c}\text { Time to } \\
\text { Intervention } \\
\text { (yrs) }\end{array}$ & Intervention & Pathology Details \\
\hline $\mathrm{F}$ & 36.72 & Solid & 1 & 2.6 & 2.07 & 5.50 & OPN & $\begin{array}{c}\text { Clear Cell, Fuhrman } \\
\text { Grade } 1 / 4\end{array}$ \\
\hline $\mathrm{F}$ & 36.72 & Solid & 1.3 & 3.8 & 3.92 & 5.50 & OPN & $\begin{array}{c}\text { Clear Cell, Fuhrman } \\
\text { Grade } 1 / 4\end{array}$ \\
\hline $\mathrm{F}$ & 36.72 & Solid & 1.9 & 3.5 & 3.09 & 5.50 & OPN & $\begin{array}{c}\text { Clear Cell, Fuhrman } \\
\text { Grade } 1 / 4\end{array}$ \\
\hline $\mathrm{F}$ & 38.75 & Solid & 1.4 & 2 & 1.10 & 6.95 & OPN & $\begin{array}{c}\text { Clear Cell, Fuhrman } \\
\text { Grade } 1-2 / 4\end{array}$ \\
\hline $\mathrm{F}$ & 40.26 & Solid & 2 & 3 & 1.96 & 5.43 & OPN & $\begin{array}{l}\text { Clear Cell, Fuhrman } \\
\text { Grade } 1-2 / 4\end{array}$ \\
\hline M & 45.39 & Solid & 2.5 & 3.8 & 2.20 & 8.42 & Cryoablation & $\begin{array}{c}\text { Clear Cell, Fuhrman } \\
\text { Grade } 1 / 4\end{array}$ \\
\hline M & 68.46 & Solid & 1.5 & 2.1 & 3.60 & 1.10 & Cryoablation & Oncocytoma \\
\hline M & 72.02 & Solid & 1.4 & 2.3 & 1.33 & 4.10 & Cryoablation & NA \\
\hline $\mathrm{F}$ & 80.61 & Solid & 2.3 & 3.3 & 4.76 & 2.54 & Cryoablation & $\begin{array}{l}\text { Renal Cell } \\
\text { Carcinoma }\end{array}$ \\
\hline M & 70.81 & Solid & 1.6 & 2.8 & 4.28 & 2.87 & Cryoablation & $\begin{array}{l}\text { Renal Cell } \\
\text { Carcinoma }\end{array}$ \\
\hline M & 70.81 & Solid & 2.4 & 3.6 & 3.04 & 3.78 & RPN & $\begin{array}{l}\text { Clear Cell, Fuhrman } \\
\text { Grade 2-4 }\end{array}$ \\
\hline $\mathrm{F}$ & 74.07 & Solid & 1.8 & 2.4 & 1.97 & 2.39 & RPN & $\begin{array}{l}\text { Papillary, Fuhrman } \\
\text { Grade 2-4 }\end{array}$ \\
\hline M & 74.72 & Solid & 1.2 & 2.4 & 2.92 & 4.19 & Cryoablation & $\begin{array}{c}\text { Renal Cell } \\
\text { Carcinoma, Low } \\
\text { Grade }\end{array}$ \\
\hline $\mathrm{F}$ & 41.95 & AML & 3 & 2.8 & 0.77 & 10.48 & SE & NA \\
\hline M & 70.81 & AML & 1.9 & 2.1 & 1.50 & 2.87 & Cryoablation & $\begin{array}{l}\text { Clear Cell } \\
\text { Carcinoma }\end{array}$ \\
\hline
\end{tabular}

OPN: open partial nephrectomy; RPN: robotic partial nephrectomy; RCC: renal cell carcinoma; SE: selective embolization; NA: not available

There were no confirmed deaths from kidney cancer. However, there was a single case of unconfirmed metastatic spread in an elderly male patient with significant comorbidities, who was diagnosed with a $3.6 \mathrm{~cm}$ solid RM in the upper pole of the right kidney. Follow-up imaging at 12 months demonstrated RM growth to $5.1 \mathrm{~cm}$, and bilateral subcentimeter lung nodules. This patient subsequently developed hilar adenopathy as well, but due to his age and comorbidities, biopsy of these lesions was not performed after consultation with his oncologist. 
Figure 4 - Kaplan-Meier curve describing the annual likelihood of a renal mass requiring intervention.

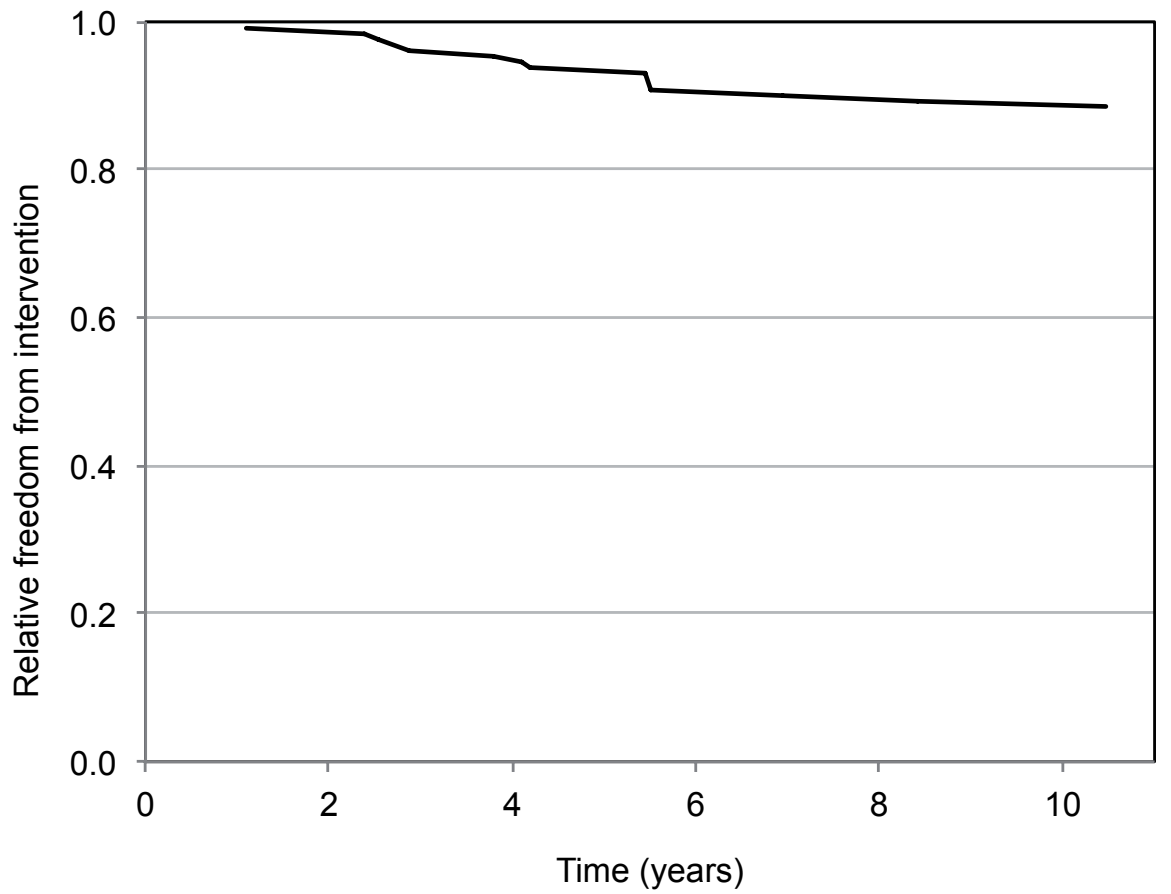

\section{DISCUSSION}

In the present study, we characterized the natural history of RMs under active surveillance and delineated which lesions may be most appropriate to manage under AS. These data may ultimately aid in the refinement of AS inclusion and termination criteria, and help manage risks associated with AS clinical management strategies.

Our data illustrate that RM growth rates under AS were lower than reported in previous studies. There were also clear differences in the MTD growth rate when RMs were stratified based upon their radiologic appearance at diagnosis. While the growth rate of AML lesions was the most rapid, they are clinically benign. AMLs are often managed with AS and subsequent intervention is commonly reserved until tumor size exceeds $4 \mathrm{~cm}$, due to increased risk of bleeding and local symptoms (10). As such, understanding the average growth rate of AMLs is useful for patient counseling. Furthermore, the epithelioid variant of AMLs can behave aggressively, further illustrating the importance of monitoring these lesions (11).

In contrast, complex cystic lesions showed essentially zero growth over the time course of the study period, while solid masses showed an intermediate, yet slow rate of growth. These solid lesions, however, were the most likely to progress to intervention during AS, with the subset of RMs requiring intervention showing a much higher than average MTD growth rate (Figure-1). Pathology from masses undergoing intervention uniformly demonstrated low-grade $(1,2)$ renal cell carcinoma, which carries a low risk of metastasis (12).

In our study, initial RM size at time of diagnosis did not prove to be a useful prognostic indicator of growth rate or metastases, with no cases of metastasis amongst the 12 RMs that were $>4 \mathrm{~cm}$ at diagnosis. This should not be interpreted to mean that $\mathrm{T} 1 \mathrm{~b}$ masses should be routinely placed under AS, however, since the majority of these were complex cystic RMs. Also, surveillan- 
ce of larger masses with subsequent growth may result in the inability to perform nephron-sparing surgery.

The slow rate of RM growth in this study may be related to its non-randomized nature, as fast growing RMs may have undergone surgery prior to 1 year under AS and, therefore, did not meet the study inclusion criteria. A separate contributing factor to the slow rates of growth may have been the use of regression analysis rather than simple arithmetic calculation to determine growth rates. Previous studies using regression analysis have reported significantly slower growth rates (approximately $1 \mathrm{~mm} /$ year) as opposed to approximately $3 \mathrm{~mm} /$ year using arithmetic methodology (12). We feel that regression provides a more accurate prediction for renal mass growth over an extended period of time, as it controls for outlier measurements which may skew growth curves constructed from relatively short follow-up intervals.

Previous studies have examined RM growth rates, and investigated potential risk factors for growth and metastases, with the majority reporting rates of metastasis approximating 1\% (Table-3). Smaldone et al. compared tumor growth kinetics, follow-up time and patient age at diagnosis in renal masses that progressed to metastatic disease but were not monitored under AS (13). They demonstrated that the mean and median age at diagnosis, initial and final MTD and initial and final tumor volume were higher in patients who progressed to metastatic disease. Chawla et al. also described predictors of tumor growth in a subset of their systematic meta-analysis. However, they could not identify a significant correlation between mass size at presentation and growth rate (3).

Table 3 - Renal mass surveillance studies and meta-analyses.

\begin{tabular}{|c|c|c|c|c|c|c|c|c|c|}
\hline & $\begin{array}{l}\text { §Smaldone et } \\
\text { al. (13) }\end{array}$ & $\begin{array}{l}\text { §Chawla et } \\
\text { al. (3) }\end{array}$ & $\begin{array}{c}\text { Bosniak et } \\
\text { al. (16) }\end{array}$ & $\begin{array}{l}\text { Crispen et } \\
\text { al. (17) }\end{array}$ & $\begin{array}{l}\text { Chawla et } \\
\text { al. }(3)^{\mu}\end{array}$ & $\begin{array}{l}\text { Mason et } \\
\text { al. (12) }\end{array}$ & $\begin{array}{l}\text { Jewett et } \\
\text { al. (18) }\end{array}$ & $\begin{array}{l}\text { Volpe et } \\
\text { al. (19) }\end{array}$ & $\begin{array}{l}\text { Present } \\
\text { study }\end{array}$ \\
\hline \# patients/\# masses & $259 / 284$ & $\mathrm{NA} / 234$ & $37 / 40$ & $154 / 172$ & $61 / 49$ & $82 / 84$ & $127 / 151$ & $29 / 32$ & $114 / 131$ \\
\hline Mean age (yrs.) & $66.6 \pm 12$ & NA & 65 & 69 & 71 & 74 & 73 & 55 & 65.4 \\
\hline Gender M/F & NA & NA & $11 / 26$ & $43 / 111$ & $12 / 36$ & $31 / 51$ & NA & NA & $54 / 60$ \\
\hline $\begin{array}{l}\text { Mean follow-up time } \\
\text { (months) }\end{array}$ & 33.5 & 34 & 44 & 31 & 34 & $36^{*}$ & 28 & $27.9^{*}$ & $4.2 \pm 2.6$ \\
\hline Intervention $\mathrm{n} ;(\%)$ & NA & NA & $26(65)$ & $20(32)$ & $131(46)$ & $\begin{array}{c}19 \\
(23.1)^{\star \star}\end{array}$ & $18(1.1)$ & $9(28)$ & $11.5 \%$ \\
\hline Growth rate (cm/yr) & 0.31 & 0.28 & 0.36 & 0.29 & 0.28 & 0.25 & 0.13 & 0.1 & $0.07 \pm 0.3 ¥$ \\
\hline Number of zero growth rate & 65 & NA & NA & 45 & NA & NA & NA & 5 & $4(3 \%)$ \\
\hline $\begin{array}{l}\text { Radiologic features (solid/ } \\
\text { cystic) }\end{array}$ & $85.4 \% / 14.6 \%$ & NA & NA & $147 / 26$ & NA & $70 / 14$ & NA & $25 / 7$ & NA \\
\hline Mean final size $(\mathrm{cm})$ & $3 \pm 1.6$ & NA & NA & NA & NA & $2.9^{*}$ & NA & NA & $2.3 \pm 1.5$ \\
\hline \# pathologic findings & 133 & 91 & 26 & 66 & 21 & 19 & 117 & 9 & NA \\
\hline \# RCC & 95 & 81 & 22 & 57 & 17 & 14 & 79 & 8 & NA \\
\hline \# benign lesions & $14^{\star * *}$ & 10 & 4 & 9 & 4 & 0 & 14 & 1 & NA \\
\hline \# metastases $n ;(\%)$ & $18(6.3)$ & $2(1)$ & 0 & $2(1.3)$ & $3(1)$ & $1(1.2)$ & $2(0.9)$ & 0 & 0 \\
\hline
\end{tabular}

§: Meta-analyses; NA: not available; ${ }^{*}$ Only the median value is presented; ${ }^{*} 7$ patients underwent biopsy and 12 underwent surgery. There was no statement about overlapping of interventions; ${ }^{* *}$ Only 12 oncocytoma and 2 angiomyolipoma were reported; $\mathbf{~}:$ Statistically not significant from zero growth; $\boldsymbol{\mu :}$ FCCC institutional experience results were retrieved from the systematic review results. 
Importantly, mean growth rate of pathologically proven benign lesions (mostly oncocytomas) and RCC variants did not differ statistically.

The strengths of our study include a relatively large single center sample size and follow-up interval, and the inclusion of a number of RMs $>4 \mathrm{~cm}$ in size. In addition, the stratification of RMs based on radiologic appearance enabled us to discern the low progression rate of cystic masses. Limitations of the present study include a lack of randomization and subsequent selection bias of patients on AS. The average patient age and CCI scores were relatively high in our cohort and so our findings may not be externally valid to younger and healthier cohorts of RM patients. Our findings may also not be directly applicable to patients with a genetic predisposition to aggressive renal cell carcinoma variants such as hereditary leiomyomatosis and renal cell carcinoma (HLRCC) and succinate dehydrogenase mutation associated kidney cancer (14). An additional potential limitation was our reliance on radiological characteristics to identify potentially malignant lesions, rather than pathology data from RM biopsies. While biopsies were performed on only a small number of patients, improved biopsy yield has led to a recent shift to obtaining biopsies when clinically indicated.

Patient follow-up procedures consisted of a variety of CT, MRI and US imaging. Although we routinely use US when feasible, based upon RM visibility and patient body habitus, and the majority of our patients were imaged at 6 month intervals, we did not prospectively employ a standardized protocol for follow-up imaging. A prospective study utilizing a single cross-sectional imaging modality over a standardized follow-up interval would be ideal, but perhaps not feasible due to costs, variability in renal function and concerns over radiation exposure. Additionally, the favorable clinical outcomes demonstrated in the present study indicate that this may be the preferred imaging modality in terms of cost and safety for AS protocols. Furthermore, RM size using US correlated well with size on CT or MRI in our patients, and in a previous study as well (15). As such, improved AS strategies may ultimately reduce the number of imaging studies required and decrease patient exposure to radiation.
Our retrospective analysis may aid in the refinement of a risk stratification protocol for patients under RM active surveillance, possibly in conjunction with renal mass biopsy and genomic testing to identify higher risk RMs. An improved AS treatment paradigm should promote the goal of nephron sparing by avoiding intervention in masses with a low risk of progression. Patients with low risk RMs may also be followed at longer intervals, resulting in fewer office visits.

\section{CONCLUSIONS}

Our data from the active surveillance of RMs over a $>3$ year median follow-up period demonstrate a low rate of tumor growth, with complex cystic masses exhibiting nearly zero net growth. Solid masses exhibited the highest growth rate, and were also the most likely to trigger surgical intervention. A nephron sparing approach for the management of incidental RMs should routinely include AS as an option in appropriately selected patients. Future studies are needed to delineate which RMs are most suitable for AS, particularly in younger patients.

\section{ABBREVIATIONS}
$\mathrm{RM}=$ Renal mass
AML = Angiomyolipoma
AS = Active surveillance
US = Ultrasonography
$\mathrm{CT}=$ Computerized tomography
MRI = Magnetic resonance imaging
RCC $=$ Renal cell carcinoma
$\mathrm{CCI}=$ Charlson comorbidity index
HLRCC = Hereditary Leiomyomatosis and Renal Cell Cancer

\section{CONFLICT OF INTEREST}

None declared.

\section{REFERENCES}

1. Hollingsworth JM, Miller DC, Daignault S, Hollenbeck BK: Rising incidence of small renal masses: a need to reassess treatment effect. J Natl Cancer Inst. 2006; 98: 1331-4. 
2. Chiu Y, Chiu AW: Renal preservation therapy for renal cell carcinoma. Int J Surg Oncol. 2012; 2012: 123596.

3. Chawla SN, Crispen PL, Hanlon AL, Greenberg RE, Chen DY, Uzzo RG: The natural history of observed enhancing renal masses: meta-analysis and review of the world literature. J Urol. 2006; 175: 425-31.

4. Volpe A, Cadeddu JA, Cestari A, Gill IS, Jewett MA, Joniau $S$, et al.: Contemporary management of small renal masses. Eur Urol. 2011; 60: 501-15.

5. Cairns P: Renal cell carcinoma. Cancer Biomark. 2010; 9: 461-73

6. Mues AC, Landman J: Small renal masses: current concepts regarding the natural history and reflections on the American Urological Association guidelines. Curr Opin Urol. 2010; 20: 105-10.

7. AUA clinical guidelines: guideline for management of the clinical stage 1 renal mass. 2009. pp. 1-76.

8. Thomas AA, Campbell SC: Small renal masses: toward more rational treatment. Cleve Clin J Med. 2011; 78: 539-47.

9. Hollingsworth JM, Miller DC, Daignault S, Hollenbeck BK: Five-year survival after surgical treatment for kidney cancer: a population-based competing risk analysis. Cancer. 2007; 109: 1763-8.

10. Sooriakumaran $P$, Gibbs $P$, Coughlin G, Attard V, Elmslie F, Kingswood C, et al.: Angiomyolipomata: challenges, solutions, and future prospects based on over 100 cases treated. BJU Int. 2010; 105: 101-6.

11. Thompson RH, Hill JR, Babayev Y, Cronin A, Kaag M, Kundu $S$, et al.: Metastatic renal cell carcinoma risk according to tumor size. J Urol. 2009; 182: 41-5.
12. Mason RJ, Abdolell M, Trottier G, Pringle C, Lawen JG Bell DG, et al.: Growth kinetics of renal masses: analysis of a prospective cohort of patients undergoing active surveillance. Eur Urol. 2011; 59: 863-7.

13. Smaldone MC, Kutikov A, Egleston BL, Canter DJ, Viterbo $\mathrm{R}$, Chen DY, et al.: Small renal masses progressing to metastases under active surveillance: a systematic review and pooled analysis. Cancer. 2012; 118: 997-1006.

14. Ricketts CJ, Shuch B, Vocke CD, Metwalli AR, Bratslavsky G, Middelton L.: Succinate dehydrogenase kidney cancer: an aggressive example of the Warburg effect in cancer. J Urol. 2012; 188: 2063-71.

15. Mucksavage P, Ramchandani P, Malkowicz SB, Guzzo TJ: Is ultrasound imaging inferior to computed tomography or magnetic resonance imaging in evaluating renal mass size? Urology. 2012; 79: 28-31.

16. Bosniak MA, Birnbaum BA, Krinsky GA, Waisman J: Small renal parenchymal neoplasms: further observations on growth. Radiology. 1995; 197: 589-97.

17. Crispen PL, Viterbo R, Boorjian SA, Greenberg RE, Chen DY, Uzzo RG: Natural history, growth kinetics, and outcomes of untreated clinically localized renal tumors under active surveillance. Cancer. 2009; 115: 2844-52.

18. Jewett MA, Mattar K, Basiuk J, Morash CG, Pautler SE, Siemens DR, et al.: Active surveillance of small renal masses: progression patterns of early stage kidney cancer. Eur Urol. 2011; 60: 39-44.

19. Volpe A, Cadeddu JA, Cestari A, Gill IS, Jewett MA, Joniau $S$, et al.: Contemporary management of small renal masses. Eur Urol. 2011; 60: 501-15.

Correspondence address: Peter Haddock, MD

Hartford Hospital healthcare Group - Urology 85 Seymour Street Hartford Connecticut 06106, United

States

Fax: +1 860 947-8500

E-mail: peter.haddock@hcchealth.org 